Marquette University

e-Publications@Marquette

Spring 2007

\title{
How Do Antitobacco Campaign Advertising and Smoking Status Affect Beliefs and Intentions? Some Similarities and Differences Between Adults and Adolescents
}

\author{
Andrea Heintz Tangari \\ Wayne State University \\ Scot Burton \\ University of Arkansas \\ J. Craig Andrews \\ Marquette University, craig.andrews@marquette.edu \\ Richard G. Netemeyer \\ University of Virginia - Main Campus
}

Follow this and additional works at: https://epublications.marquette.edu/market_fac

Part of the Marketing Commons

\section{Recommended Citation}

Tangari, Andrea Heintz; Burton, Scot; Andrews, J. Craig; and Netemeyer, Richard G., "How Do Antitobacco Campaign Advertising and Smoking Status Affect Beliefs and Intentions? Some Similarities and Differences Between Adults and Adolescents" (2007). Marketing Faculty Research and Publications. 58. https://epublications.marquette.edu/market_fac/58 


\title{
How Do Antitobacco Campaign Advertising and Smoking Status Affect Beliefs and Intentions? Some Similarities and Differences Between Adults and Adolescents
}

\author{
Andrea H. Tangari, Scot Burton, J. Craig Andrews, and \\ Richard G. Netemeyer
}

This article presents two studies that examine similarities and differences with respect to how adults and adolescents process and respond to information in an antitobacco ad campaign. Study 1 examines (1) the effects of antitobacco advertising campaign measures (e.g., campaign advertisement integration, perceived strength of ad-based messages, attitude toward the ad campaign) on four key adult antismoking beliefs and (2) the influence of these campaign evaluations and beliefs on smokers' intentions to quit smoking. Hierarchical regression results show that antismoking ad campaign reactions explain substantial additional variance in beliefs about tobacco industry deceptiveness, smoking addictiveness, harmfulness of secondhand smoke, and restrictions on smoking at different public venues. The findings also show that the campaign variables as a whole are positively related to intentions to quit smoking, beyond the variance that is explained by demographics. In Study 2, the authors replicate and extend these findings for the campaign using similar measures and procedures for a sample of more than 900 adolescents. They draw comparisons between these adult and adolescent findings and offer some implications for potential corrective advertising for consumers' beliefs about smoking that may be required of tobacco companies based on U.S. v. Philip Morris USA, Inc.

$\mathbf{T}$ he costs of tobacco use in the United States are enormous. For example, tobacco use is the leading preventable cause of death in the country, contributing to almost 440,000 deaths each year and resulting in $\$ 75$ billion per year in direct medical costs, $\$ 90$ billion in lost productivity, and approximately $\$ 160$ billion in total tobaccorelated disease costs (Centers for Disease Control [CDC] 2006). Tobacco use also affects youths in the Untied States. Approximately 4.5 million adolescents smoke cigarettes, and current tobacco trends indicate that more than 6 million

Andrea H. Tangari is a doctoral student, Department of Marketing and Logistics (e-mail@ atangari@walton.uark.edu), and Scot Burton is Professor and Wal-Mart Chair in Marketing (e-mail: sburton@ walton.uark.edu), Department of Marketing and Logistics, Sam M. Walton College of Business, University of Arkansas. J. Craig Andrews is Professor and Charles H. Kellstadt Chair in Marketing, Department of Marketing, College of Business Administration, Marquette University (e-mail: craig.andrews@marquette.edu).Richard G. Netemeyer is Professor and Ralph A. Beaton Chair of Free Enterprise, McIntire School of Commerce, University of Virginia (e-mail: rgn3p@virginia. edu). The authors gratefully acknowledge the help of the Wisconsin Tobacco Control Board, BVK-McDonald, Market Strategies, Paul Moberg, Ann Christiansen, David Ahrens, and Amanda Riemer in the campaign planning and data collection process. children will die prematurely because of smoking-related illnesses (American Lung Association 2003). In an effort to reduce such costs, the Subcommittee on Cessation of the Interagency Committee on Smoking and Health recently issued a national action plan with ten recommendations to reduce tobacco use in the United States (Fiore et al. 2004). One recommendation is to design statewide media campaigns to decrease tobacco use and help counteract the $\$ 15$ billion spent on advertising and promotion by the tobacco industry (CDC 2006; Fiore et al. 2004).

In recent years, many states have reduced spending on tobacco prevention (Siegel 2002). Cutbacks in state spending on antitobacco campaigns have been shown to be followed by lower campaign awareness and increased susceptibility to smoking cigarettes among adolescents (CDC 2004b). However, if it is upheld, Judge Kessler's recent "Final Judgment and Remedial Order" in U.S. v. Philip Morris USA, Inc. (2006) will require corrective advertising from tobacco companies on prime-time television, newspapers, package "onserts," and retail displays that focus on messages related to beliefs for which consumers may have been misled by tobacco company marketing. The ruling would require massive promotional expenditures by major tobacco companies, and it indicates the perceived importance of media campaigns as a critical aspect of tobacco control programs (Hu, Sung, and Keeler 1995). The overall 
goal of such campaigns is to counteract what are viewed as deceptive marketing practices that may have contributed to erroneous beliefs about smoking and to establish (or reinforce) current negative beliefs about smoking in attempts to decrease smoking rates. Therefore, it is important to understand the beliefs of smokers and nonsmokers about smoking and the relationship among evaluations of counteradvertising campaigns, antismoking beliefs, and smoking.

Consistent with the subcommittee's recommendation and Judge Kessler's recent order, Study 1 examines the effects of reactions to a major state antitobacco campaign on adults' beliefs about smoking (e.g., addictiveness, harmfulness of secondhand smoke) and consideration of quitting. We focus on two primary questions: (1) Do integrated advertising campaign measures influence key antismoking beliefs, and does this influence vary across consumers' smoking status? and (2) What is the effect of consumers' evaluations of the campaign and antismoking beliefs on smokers' consideration of quitting? In Study 2, we extend these questions to the adolescent market and broaden our analyses to examine the relationship between campaign evaluations and adolescents' intentions to smoke.

\section{Study 1 \\ Background and Hypotheses}

\section{The Importance of Consumers' Antismoking Beliefs}

In the statewide media campaign we address herein, five integrated advertisements focusing on three primary beliefs related to smoking were targeted at the adult market. These specific belief themes are commonly used in antismoking advertising and are as follows: (1) the tobacco industry's deceptive ad practices to induce people to smoke, (2) the addictiveness of smoking, and (3) the harmful nature of environmental (secondhand) tobacco smoke. In addition, we examine a fourth belief theme-bans on smoking in public locations - a concern that is directly related to environmental tobacco smoke (ETS) and its effects (Brownson et al. 1995; Foster 2005; Koch 2005).

These four beliefs are important targets for public policy, antismoking advertising, and public health campaigns and are closely related to several beliefs for which corrective statements are mandated in Judge Kessler's recent order. In her 1683-page final ruling, she stresses concerns about tobacco's addictiveness, ETS, marketing targeted at adolescents, and deceptive practices related to the harmfulness of smoking. For example, she states,

[This case] is about an industry, and in particular these Defendants, that survives, and profits, from selling a highly addictive product which causes diseases that lead to a staggering number of deaths per year, an immeasurable amount of human suffering and economic loss, and a profound burden on our national health care system. Defendants have known many of these facts for at least 50 years or more. Despite that knowledge, they have consistently, repeatedly, and with enormous skill and sophistication, denied these facts to the public, to the Government, and to the public health community. Moreover, in order to sustain the economic viability of their companies, Defendants have denied that they marketed and advertised their products to children under the age of 18 and to young people between the ages of 18 and 21 in order to ensure an adequate supply of "replace- ment smokers" as older ones fall by the wayside through death, illness, or cessation of smoking." (U.S. v. Philip Morris USA, Inc. 2006, pp. 3-4)

As this statement suggests, for many years, the tobacco industry argued that nicotine was not addictive and that the industry did not target young consumers to smoke. However, the release of the industry documents as part of the Master Tobacco Settlement revealed that the tobacco industry had known for many years that nicotine was addictive and that adolescent consumers were an important target market for the industry (Cohen 2000; World Health Organization [WHO] 2006). A notable example was in 1994 when seven chief executive officers of U.S. tobacco companies each testified to the U.S. House Energy \& Commerce Subcommittee on Health and Environment that they did not believe that nicotine was addictive. Similarly, the documents reveal that because the companies knew that approximately two-thirds of adult smokers begin smoking before the age of 18 , it was critical to focus on these adolescents with targeted advertising and promotion (WHO 2006). ${ }^{1}$ It has been further concluded that tobacco advertising and promotional activities are linked to the onset of smoking in adolescents and that advertising exposure level is predictive of smoking levels among adolescents (Framework Convention Alliance for Tobacco Control 2006). Consistent with these documents, the recent order from Judge Kessler requires a corrective statement from the tobacco companies about "the addictiveness of smoking and nicotine."

The settlement documents are also enlightening in terms of information revealed about ETS. Although initially contested, for more than a decade, the link between ETS and health has been well documented (CDC 2006). For example, ETS is associated with several health effects, including heart disease mortality and chronic diseases, such as childhood asthma (National Cancer Institute 1999). In contrast, the documents reveal that companies obscured the potential harm of ETS because if beliefs about its link with health were confirmed, "bans on smoking in public would be sure to follow and this would be very bad for the tobacco companies' business" (WHO 2006). Because of perceived deception regarding the adverse effects of secondhand smoke, the harmfulness of ETS is a belief targeted for corrective advertising in the final opinion of Judge Kessler.

Thus, the settlement documents reveal that the addictiveness of tobacco and the potential harmfulness of ETS are consumer beliefs that the tobacco companies attempted to influence and that some companies have not responded as truthfully as possible to criticism that they targeted, marketed, and advertised cigarettes to adolescents in persuasive communications. Given such company actions, a motivation behind the corrective advertising required in Judge Kessler's final ruling, as well as an objective of other antismoking campaigns, is the desire to counter efforts of the tobacco companies in terms of beliefs about addictiveness

1For example, the settlement documents (WHO 2006) reveal adolescent targeting in statements such as the following: "To ensure increased and longer-term growth for Camel filter, the brand must increase its share penetration among the 14-24 age group" (R.J. Reynolds marketing analyst, 1975), and "the base of our business is the high school student" (Lorillard memo on sales of Newport cigarettes, 1978). 
and ETS and to affect perceptions related to industry deceptiveness. In addition, we also address consumers' beliefs about government laws that protect consumers from ETS. Currently, approximately $39 \%$ of U.S. consumers live in areas that have local or statewide limits on smoking, and there are approximately 2000 such laws in place today, compared with only 200 in 1985 (Koch 2005). In 2005, six states enacted indoor smoking bans, a number greater than in any prior year (Koch 2005). Issues related to ETS and indoor bans are of interest and relevant to both smokers and nonsmokers. In summary, given the importance and interest in beliefs about addictiveness, deceptive practices of the tobacco companies, ETS, and smoking bans in public places, these four antismoking beliefs serve as the dependent variables in our first set of predictions.

\section{Predictions About Influences on Antismoking Beliefs}

Although substantial literature supports the notion that consumers' smoking behaviors should be negatively related to their antismoking beliefs, research and theory suggests that there are differences across the types of beliefs. For example, social judgment theory and empirical findings indicate that consumers often counterargue or ignore messages that are not consistent with their behaviors and attitudes (Petty and Cacioppo 1981). Such messages are contrasted with salient attitudes and beliefs, effectively reducing the impact of a persuasive message (e.g., Sherif and Hovland 1961). With regard to smoking research, findings show that smokers tend to discount the risks and negative consequences of smoking (Romer and Jamieson 2001).

However, some beliefs may be less susceptible to contrasting and counterargumentation than others. Despite historical industry efforts and denials, the addictiveness of nicotine and smoking is well recognized by smokers and difficult to dispute, given the massive publicity and information communicated by the media and public health groups over the past 40 years (Jamieson and Romer 2001). However, beliefs about minimizing ETS by placing bans or restrictions on smoking in public locations (e.g., indoor work areas, sporting events, bars and taverns) are likely to differ more substantially between smokers and nonsmokers. Opinion poll results show that $32 \%$ of smokers agree that smoking should be banned in restaurants, compared with $70 \%$ of nonsmokers (McMillen et al. 2003). Recent evidence points to some effectiveness of bans; employees in workplaces with smoking bans have higher rates of smoking cessation than employees in workplaces in which smoking is permitted, though relapse is similar between these two groups of employees (Longo et al. 2001). Thus, although adults' smoking status should be negatively related to all beliefs, we predict that it will be more strongly (negatively) related to bans on smoking in public locations than to perceptions of the addictiveness of smoking. ${ }^{2}$

$\mathrm{H}_{1 \mathrm{a}}$ : Smoker status is negatively related to beliefs about (i) tobacco industry deceptiveness, (ii) smoking addictiveness, (iii) harmfulness of secondhand smoke, and (iv) restricting smoking at different public venues.

\footnotetext{
${ }^{2}$ Although not explicitly postulated, we anticipate that smoking status will be more negatively related to deceptiveness and secondhand smoke than to addictiveness but less negatively related to restrictions on smoking.
}

$\mathrm{H}_{1 \mathrm{~b}}$ : Smoker status explains (i) the greatest variance in beliefs about restricting smoking at different public venues and (ii) the least variance in beliefs about smoking addictiveness.

$\mathrm{H}_{2}$ and $\mathrm{H}_{3}$ address the relationship between attitude toward (or liking of) an ad campaign and antismoking beliefs. Although few academic studies examine effects of attitudes toward an ad campaign, prior studies have indicated that attitude toward an ad is positively linked to beliefs about the brand (Lutz 1985). For example, Brown and Stayman (1992) report a positive association between attitude toward the ad and consumer cognitions, and ad-copy-test researchers have reported that liking of or affect toward an ad has a substantial impact on effectiveness. The results from the Advertising Research Foundation's copy-test validity project indicate that the liking of an ad was the single best copy-test predictor of campaign success (Haley and Baldinger 1991).

We propose that the strength of the positive effect of campaign attitude differs between smokers and nonsmokers. In general, smokers' antismoking beliefs are not positive compared with nonsmokers' antismoking beliefs, as we suggest in $\mathrm{H}_{1}$. Given weaker antismoking beliefs for smokers, when a campaign is favorably perceived, it should have substantial opportunity to affect antismoking beliefs, compared with nonsmokers. That is, adult nonsmokers already have relatively strong antismoking beliefs, and a favorable attitude toward the campaign seems more likely to reinforce these existing beliefs than to lead to a substantial incremental effect. This rationale suggests an interaction between smoking status and attitude toward the campaign that is positive in its relationship to antismoking beliefs.

$\mathrm{H}_{2}$ : Beyond the influence of smoker status, attitude toward the ad campaign is positively related to beliefs about (a) tobacco industry deceptiveness, (b) smoking addictiveness, (c) harmfulness of secondhand smoke, and (d) restricting smoking at different public venues.

$\mathrm{H}_{3}$ : Smoker status moderates the effect of the attitude toward the ad campaign. Specifically, attitude toward the ad campaign is more positively related to (a) tobacco industry deceptiveness, (b) smoking addictiveness, (c) harmfulness of secondhand smoke, and (d) restricting smoking at different public venues, for smokers than for nonsmokers.

Considerable literature demonstrates that strong message arguments have greater effects on ensuing beliefs than weaker arguments (Petty and Caccioppo 1986; Rucker and Petty 2006). Although this literature on argument strength often focuses on interaction effects, both academics and practitioners recognize the importance of using strong messages to influence persuasion. Thus, the perceived strength of the counteradvertising messages should be positively related to the antismoking beliefs.

$\mathrm{H}_{4}$ : The perceived strength of ad-based messages is positively related to beliefs about (a) tobacco industry deceptiveness, (b) smoking addictiveness, (c) harmfulness of secondhand smoke, and (d) restricting smoking at different public venues.

Most current marketing and promotion texts advocate the use of integrated marketing communications (IMC) to add 
value to and enhance the effectiveness of marketing communications (e.g., Shimp 2007). It is argued that the synergy and focus of such programs offer increased clarity, consistency, and impact of the messages communicated to consumers (McGrath 2005; Schultz, Tannenbaum, and Lauterborn 1993). On the basis of these IMC principles, we examine the effects of the level of exposure to different antismoking campaign advertisements. As Haugvedt and colleagues (1994) find, the use of different ad repetition strategies using ad variation is one way to increase the strength of ad-based attitudes in resisting counterpersuasion influences. It is also argued that multiple ad exposures provide people with more opportunity to think about the message, develop beliefs about the message, and develop greater/stronger brand and attribute associations. Thus, we predict that exposure to different advertisements within the campaign will enhance the various beliefs targeted in an overall campaign effort; that is, consumers' exposure to a greater number of antismoking messages within a campaign will have a positive effect on the four antismoking beliefs $\left(\mathrm{H}_{5}\right)$.

However, $\mathrm{H}_{6}$ predicts that the strength of the integrative effect of awareness of multiple advertisements in a campaign will vary across smokers and nonsmokers. As argued previously, we believe that, in general, a single persuasive attempt is less likely to alter the smoking beliefs of smokers than those of nonsmokers. A greater effort through multiple persuasive messages is likely to be required to affect smokers' antismoking beliefs, whereas nonsmokers are more likely to assimilate antismoking messages without counterargumentation. This suggests that the number of campaign advertisements viewed has a somewhat stronger effect on smokers than nonsmokers.

$\mathrm{H}_{5}$ : The number of advertisements in a campaign that consumers are aware of is positively related to their beliefs about (a) tobacco industry deceptiveness, (b) smoking addictiveness, (c) harmfulness of secondhand smoke, and (d) restricting smoking at different public venues.

$\mathrm{H}_{6}$ : Smoker status moderates the effect of the ad campaign awareness. The number of campaign advertisements viewed is more positively related to beliefs about (a) tobacco industry deceptiveness, (b) smoking addictiveness, (c) harmfulness of secondhand smoke, and (d) restricting smoking at different public venues, for smokers than for nonsmokers.

\section{Effects on Consideration of Quitting Smoking}

In addition to influencing beliefs about smoking, an objective of most counteradvertising campaigns is to encourage current smokers to attempt to quit. $\mathrm{H}_{7}$ and $\mathrm{H}_{8}$ focus on the effects of the target ad campaign constructs and antismoking beliefs on smokers' consideration of quitting.

The advertising literature argues that advertisements work on both cognitive and affective levels (Vakratsas and Ambler 1999); that is, both affective (e.g., attitude toward the ad) and cognitive responses can have separate effects on consumer intent (Burke and Edell 1989; Zinkhan and Burton 1989). In the Advertising Research Foundation ad-copytest project (Haley and Baldinger 1991), ad likeability (i.e., ad affect) was viewed as the strongest copy-test predictor of ad campaign success. Finally, according to IMC principles and prior research, the integration of advertisements from a campaign should enhance and reinforce the effects of the multiple persuasive messages on behavioral intentions. Thus, $\mathrm{H}_{7}$ predicts that the perceived strength of the ad messages, attitude toward the ad campaign, and the number of advertisements that consumers are aware of will all have a positive influence on smokers' consideration of quitting.

A large body of empirical research indicates that beliefs about a behavior are related to the intent to perform that behavior (Ajzen and Fishbein 1980), and aggregate beliefs about smoking consequences have been shown to be predictors of adolescent smoking intentions (Andrews et al. 2004). Thus, we predict that the individual antismoking beliefs will be positively related to consideration of quitting smoking.

$\mathrm{H}_{7}$ : The ad campaign-based variables of (a) the advertising campaign attitude, (b) increased awareness of advertisements in a campaign, and (c) perceived strength of the adbased message are positively related to the consideration of quitting smoking.

$\mathrm{H}_{8}$ : Beyond the influence of the ad campaign-based measures, beliefs about (a) industry deceptiveness, (b) smoking addictiveness, (c) harmfulness of secondhand smoke, and (d) restricting smoking at different public venues are positively related to the consideration of quitting smoking.

\section{Methodology}

\section{The Antitobacco Campaign, Data Collection Procedures, and Sample}

To test our predictions, we used the Wisconsin AntiTobacco Media Campaign, a campaign funded from the state settlement with the tobacco industry. An objective of this campaign was to develop and target antismoking messages for both adult and adolescent target markets. For the television campaign targeted at adults, five specific advertisements ("Unborn/kid," "Rick Stoddard," "Drive," "Janet Sachman," and "Patrick Reynolds") were aired on television and the radio in seven major Wisconsin markets. The campaign used this series of advertisements to focus on the three primary beliefs about negative aspects of smoking (i.e., the tobacco industry's deceptive ad practices to induce people to smoke, the addictiveness of smoking, and the harmful nature of ETS). Over a seven-month period, \$6.5 million was allocated for this major antitobacco ad campaign. The specific advertisements used had been tested and run in other states, and they were designed to reflect the different antismoking belief theme types. For example, "Patrick Reynolds" features a man talking about being a part of a family of cigarette manufacturers and wanting people to know that they should not smoke (a deceptiveness theme). "Janet Sachman" depicts a former cigarette model with a coarse voice discussing how she used to try to convince people to smoke and now tells people to stop smoking (a deceptiveness theme). In "Drive," a passenger in a car lights a cigarette, and the driver veers the car off the road, making an analogy to the cigarette endangering her life (an ETS theme). "Unborn/kid" shows a pregnant women and the effect of cigarette smoke on her unborn child (an ETS theme). "Rick Stoddard" portrays a man talking about his wife dying at age 46 from smoking (an addictiveness theme).

Telephone interviews using random-digit dialing procedures were employed to collect the data. The final sample 
consisted of 1208 participants who were 18 years of age or older. ${ }^{3}$ The Council of American Survey Research Organizations' (1982) conservative formula for response rate determination (which accounts for the unknown eligibility status of some of the calls) yielded a response rate of $20.1 \%$. The introduction to the survey stated that the firm conducting the telephone interviews was doing "a survey of Wisconsin adults about their attitudes and opinions toward tobacco and other health issues," without mentioning anything directly about the ad campaign of interest. In general, respondents took between 10 and 15 minutes to complete the telephone survey.

\section{Measures}

The survey included multi-item measures of the three critical antismoking beliefs and an index of locations in which smoking should be restricted. These measures were collected near the beginning of the survey prior to any questions about the ad campaign. Antismoking beliefs were measured with four-point "strongly disagree/strongly agree" scales for the themes of (1) the harmfulness of secondhand smoke (three items; coefficient $\alpha=.81$; e.g., "Secondhand smoke is dangerous to nonsmokers"), (2) the addictiveness of smoking (two items; coefficient $\alpha=.71$; e.g., "Smoking is addictive"), and (3) the deceptiveness of the tobacco companies' ad practices (four items; coefficient $\alpha=.88$; e.g., "Tobacco companies use deceptive practices to get people hooked on smoking"). For each of these belief themes, we summed item scores and then averaged them to form an overall mean score. For the items pertaining to banning smoking in public places, respondents were asked whether they agreed that smoking should be allowed in restaurants, indoor work areas, indoor sporting events, bars and taverns, and indoor shopping areas. We coded the response for each location in which the respondent agreed that smoking should not be allowed at all as 1 and 0 otherwise. We then created an index for a restriction-on-smoking measure by summing responses for these five items.

We used smoking status as an independent variable in the initial analyses. To measure this variable, participants were asked, "Do you now smoke cigarettes every day, some days, or not at all?" We classified respondents who reported "every day" or "some days" as current smokers (coded as 1 ); we classified all others as nonsmokers (coded as 0 ). This classification resulted in 213 current smokers. Our analyses for $\mathrm{H}_{7}$ and $\mathrm{H}_{8}$ examined whether current smokers were considering quitting and asked, "Are you considering stopping smoking within the next 6 months?" $(1=$ yes, and $0=$ no). Demographic variables used as controls in our tests of predictions included measures of age, gender $(0=$ female, and $1=$ male $)$, race $(1=$ Caucasian, and $0=$ African American $/$ other), and education. The average age of respondents was 38 years, $60 \%$ of the respondents were female, $70 \%$ were Caucasian, and the modal education level was a high school graduate.

\footnotetext{
${ }^{3}$ Because of missing values, sample sizes for the regression analyses used to test $\mathrm{H}_{1}-\mathrm{H}_{6}$ ranged from 923 to 1008 . For $\mathrm{H}_{7}-\mathrm{H}_{9}$, which examined current smokers' reported intentions to quit, the sample size was 213 .
}

To assess awareness, respondents were asked questions about each of the five advertisements in the campaign. For example, for one of the advertisements ("Patrick Reynolds") that focused on deceptiveness, respondents were asked, "Do you recall seeing or hearing an ad in which a man talks about being a part of a family of cigarette manufacturers and he wants people to know they should not smoke?" (1 = yes, and $0=$ no). We summed responses to these awareness questions across the five campaign advertisements, which yielded a measure ranging between zero and five. For advertisements for which there was awareness, respondents were asked, "How much did you like the ad?" (measured on an 11-point scale anchored by "not at all" [0] and "very much" [10]). We calculated means across these items for the campaign advertisements $(\alpha=.81)$ to create the measure of attitude toward the ad campaign. We also measured the perceived strength of the ad message in conveying the targeted antismoking belief for advertisements for which respondents reported awareness. For example, for an advertisement that focused primarily on the deceptiveness theme, respondents were asked, "How did the advertisement make you feel about the tobacco industry?" They were instructed to "choose any number from 0 to 10 , where 0 means the ad made you feel the tobacco industry is not at all deceptive and 10 means the ad made you feel the tobacco industry is very deceptive." Again, we calculated means across the five advertisements $(\alpha=.80)$. Table 1 shows summary statistics and correlations among study variables.

\section{Results}

\section{Effects on Antismoking Beliefs}

To address $\mathrm{H}_{1}-\mathrm{H}_{6}$, we performed hierarchical regressions for each of the four primary antismoking belief dependent variables. Consistent with other antismoking research, we entered demographic (control) variables in the first stage of the analyses (e.g., Netemeyer, Andrews, and Burton 2005; Soliman, Pollack, and Warner 2004). In the second stage, we assessed $\mathrm{H}_{1}$ through the entry of smoking status. In the third stage, we tested $\mathrm{H}_{2}-\mathrm{H}_{6}$ through the entry of the counteradvertising campaign construct measures and interactions with smoking status. The results of the hierarchical analyses for adults appear in Table 2. (We discuss the columns in Table 2 that are related to findings for adolescents next.)

The results for Models 1 and 2 (top portion of Table 2) show findings for the demographic control variables and smoking status. There are some consistent effects across the four dependent variables for gender; the negative standardized coefficients indicate that women have stronger antismoking beliefs than men. As $\mathrm{H}_{1 \mathrm{a}}$ predicted, the addition of smoking status to the model has a significant incremental effect on all four belief measures (F-change values ranging from 8.7 to $147.6, \mathrm{ps}<.01)$. However, consistent with $\mathrm{H}_{1 \mathrm{~b}}$, the large difference in the F-change values suggests that smoking status has a larger incremental effect on beliefs about smoking restrictions than on beliefs about addictiveness. The large negative standardized coefficient for beliefs about smoking restrictions indicates that compared with beliefs such as addictiveness of tobacco or industry deceptiveness, as we anticipated, smokers are much less 
Table 1. Means, Standard Deviations, and Correlations Among Constructs: Study 1

\begin{tabular}{|c|c|c|c|c|c|c|c|c|c|c|c|c|c|c|}
\hline & M & SD & 1 & 2 & 3 & 4 & 5 & 6 & 7 & 8 & 9 & 10 & 11 & 12 \\
\hline \multicolumn{15}{|l|}{ Ad Campaign } \\
\hline 1. Message strength & 8.02 & 2.12 & 1.0 & & & & & & & & & & & \\
\hline $\begin{array}{l}\text { 2. Number of campaign } \\
\text { advertisements }\end{array}$ & 3.37 & 1.15 & .15 & 1.0 & & & & & & & & & & \\
\hline $\begin{array}{l}\text { 3. Attitude toward } \\
\text { the campaign }\end{array}$ & 7.58 & 2.34 & .64 & .13 & 1.0 & & & & & & & & & \\
\hline \multicolumn{15}{|l|}{ Antismoking Beliefs } \\
\hline 4. Deceptiveness & 2.99 & .63 & .47 & .10 & .30 & 1.0 & & & & & & & & \\
\hline 5. Addictiveness & 3.48 & .50 & .33 & .12 & .27 & .48 & 1.0 & & & & & & & \\
\hline 6. Secondhand smoke & 3.30 & .58 & .48 & .11 & .36 & .50 & .54 & 1.0 & & & & & & \\
\hline 7. Smoking ban & 3.04 & 1.56 & .38 & .05 & .32 & .41 & .28 & .50 & 1.0 & & & & & \\
\hline \multicolumn{15}{|l|}{ Smoking/Demographics } \\
\hline 8. Smoking status & - & - & -.23 & -.05 & -.23 & -.26 & -.13 & -.32 & -.38 & 1.0 & & & & \\
\hline 9. Race & - & - & -.08 & .05 & -.14 & .00 & .02 & .04 & .04 & -.05 & 1.0 & & & \\
\hline 10. Age & 36.0 & 17.1 & -.02 & -.03 & .05 & .01 & .03 & -.07 & .04 & -.11 & .01 & 1.0 & & \\
\hline 11. Education & - & - & -.04 & .01 & -.02 & .05 & .06 & .05 & .05 & -.17 & .15 & .05 & 1.0 & \\
\hline 12. Gender & - & - & -.16 & -.11 & -.20 & -.07 & -.11 & -.15 & -.13 & .06 & .13 & -.05 & .00 & 1.0 \\
\hline
\end{tabular}

Notes: Correlations of approximately .07 or higher are significant $(p<.05$ or better).

likely than nonsmokers to support greater restrictions on smoking. 4

Model 3 addressed the incremental effects of the ad campaign construct measures, beyond the effect of smoking status and demographics, on the four dependent variables. In general, the model statistics at the bottom of Table 2 indicate that the overall effects of the ad campaign measures are significant for each of the four belief dependent measures ( $p s<.01$ for all). The pattern of positive coefficients associated with the campaign measures indicates a positive influence on antismoking beliefs.

$\mathrm{H}_{2}$ predicted that the incremental impact of attitude toward the ad campaign would be positively related to the antismoking belief measures. The results of Model 3 show general support for this prediction. Although the coefficients across all four belief variables are positive (as we predicted), they are significant for addictiveness, restrictions on smoking (both $p$ s $<.01)$, and secondhand smoke $(p<.05)$ but are nonsignificant for tobacco industry deceptiveness. $\mathrm{H}_{3}$ addressed the potential moderating effect of smoking status on the positive influence of attitude toward the ad campaign. Following procedures that Aiken and West (1991) suggest, we mean-centered the smoking status, attitude toward the ad campaign, and number of campaign advertisements before creating the interaction terms of inter-

${ }^{4} \mathrm{~T}$-tests assessing the mean differences for the antismoking beliefs for smokers and nonsmokers reinforce these regression findings. There is greater similarity in means for addictiveness $\left(\mathrm{M}_{\text {smokers }}=3.37\right.$, and $\left.\mathrm{M}_{\text {nonsmokers }}=3.52 ; \mathrm{t}=4.0, p<.01\right)$ than for restrictions on smoking $\left(\mathrm{M}_{\text {smokers }}=2.08\right.$, and $\left.\mathrm{M}_{\text {nonsmokers }}=3.42 ; \mathrm{t}=12.7, p<.01\right)$. For deceptiveness, means for smokers and nonsmokers are 2.71 and 3.08, respectively $(\mathrm{t}=7.7, p<.01)$, and for secondhand smoke, means for smokers and nonsmokers are 3.0 and 3.41, respectively $(\mathrm{t}=9.8, p<.01)$. est in $\mathrm{H}_{3}$ and $\mathrm{H}_{6} \cdot{ }^{5}$ There is no support for the positive influence of smoking status on the effect of attitude toward the ad campaign; thus, the results fail to support $\mathrm{H}_{3}$. For restrictions on smoking, the coefficient is negative and significant $(p<.05)$.

$\mathrm{H}_{4}$ offered predictions about the incremental impact of the perceived strength of the ad-based messages, after we accounted for the effects of demographic (control) variables and smoking status. As Table 2 indicates, these results are all positive and significant $(p<.01)$, in support of $\mathrm{H}_{4}$. $\mathrm{H}_{5}$ and $\mathrm{H}_{6}$ pertain to the direct and interaction effects of increased awareness of the multiple advertisements in the campaign. The findings for the direct effect of the number of advertisements are relatively weak; there is significant support only for effects on addictiveness $(p<.05)$ and marginal support for secondhand smoke $(p<.10)$. In terms of the potential moderating effect of smoking status on the influence of the number of campaign advertisements and the ad message strength, there is a stronger, positive influence for the number of campaign advertisements viewed for smokers than for nonsmokers for industry deceptiveness $(p<.05)$, secondhand smoke $(p<.10)$, and restrictions on smoking $(p<.10)$. The findings offer partial support for the proposed predictions related to greater awareness for the campaign advertisements.

In terms of the overall campaign, the incremental effect of the combined ad measures is significant for each of the four belief measures (F-change values range from 14.8 to 44.9,

\footnotetext{
${ }^{5}$ Mean centering is a procedure that is advocated to reduce potential adverse effects of multicollinearity when examining interactions in regression (Aiken and West 1991). Variables used to create the interaction term are "centered" by subtracting the respective mean scores from the original independent variables (thus creating an overall mean score of zero).
} 


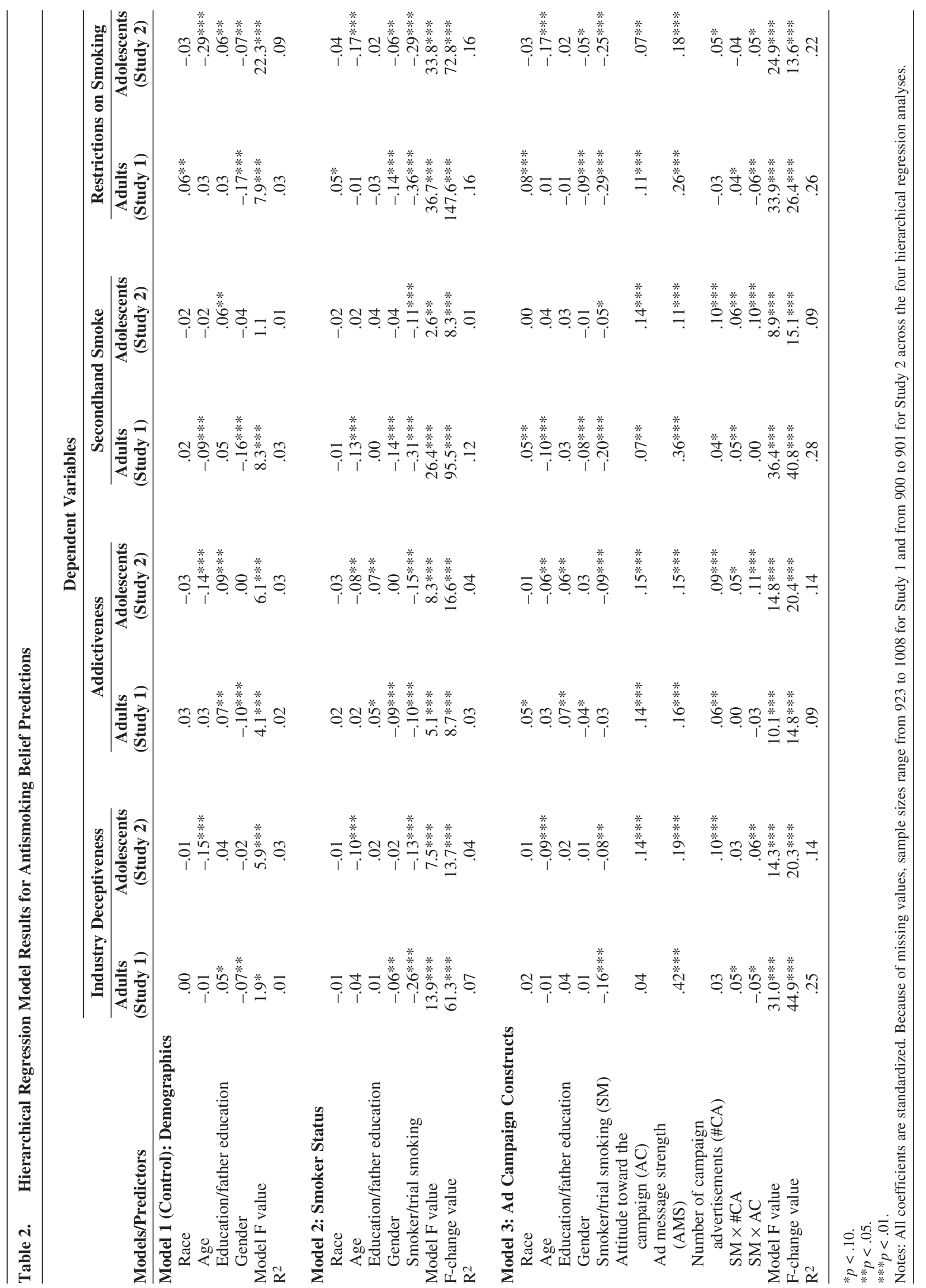


$p<.01)$. The R-square values for the beliefs before the addition of the ad campaign variables in Model 3 ranged from .03 (addictiveness) to .16 (restrictions on smoking). The inclusion of the ad campaign variables resulted in increases in the variance explained ranging from .06 (addictiveness) to .18 (tobacco industry deceptiveness), suggesting moderate to large effects (Cohen 1977).

\section{Effects on Consideration of Quitting Smoking}

To test the predicted relationships between effect of the ad campaign measures and the antismoking belief measures on smokers' consideration of quitting, we performed a hierarchical logistic regression. In the first model, we entered the effects of the demographic (control) variables; in the second stage, we assessed the relationship between the ad campaign and consideration of quitting $\left(\mathrm{H}_{7}\right)$; and in the third stage, we tested the incremental impact of the antismoking beliefs beyond the effect of the campaign and demographics $\left(\mathrm{H}_{8}\right)$. The results appear in Table 3.

As the first column in the Table 3 shows, gender and age are significant predictors of consideration of quitting; specifically, women and younger adults are more likely to report stronger consideration. The results for Model 2 indicate that the ad campaign measures as a group are significantly related to consideration of quitting, beyond the effects related to demographics $\left(\chi^{2}\right.$-change value $=25.4$, d.f. $=3, p<.01)$. The logistic regression coefficients for perceived ad message strength and attitude toward the campaign are both positive and significant, in support of $\mathrm{H}_{7 \mathrm{a}}$ and $\mathrm{H}_{7 \mathrm{c}}$. The coefficient for the number of campaign advertisements that consumers are aware of is positive but nonsignificant and thus does not support $\mathrm{H}_{7 \mathrm{~b}}$.

In Model 3, we included the antismoking beliefs to assess their incremental effect beyond demographics and campaign effects. As the bottom portion of Table 3 shows, these antismoking beliefs explain a significant incremental amount of variance in consideration of quitting $\left(\chi^{2}\right.$-change value $=$ 13.4 , d.f. $=4, p<.01)$. Coefficients related to tobacco industry deceptiveness and tobacco addictiveness are positive and significant, and restriction on smoking is marginally significant $(p<.10)$. These findings offer general support for the prediction that antismoking beliefs are positively related to the consideration of quitting smoking, in support of $\mathrm{H}_{8 \mathrm{a}}$ and $\mathrm{H}_{8 \mathrm{~b}}$.

\section{Discussion}

The results of Study 1 indicate that perception of ad message strength has the most consistent effect on the belief dependent variables, and attitude toward the campaign has a significant effect for three of the four variables. Adult consumers' ad campaign reactions explained a significant level of variance in beliefs about tobacco industry deceptiveness, smoking addictiveness, harmfulness of secondhand smoke, and restrictions on smoking at different public venues. Perhaps more important, the campaign variables as a group are positively related to the consideration of quitting smoking. Furthermore, both the affective attitude toward the campaign and the cognitive message strength measures continue to show some effect even after the focal antismoking beliefs are included as predictors in the hierarchical logistic model.

Although several of these results appear encouraging for this sample of adult consumers, many counteradvertising campaigns are also concerned about the effects on adolescent consumers, a target market that represents future potential smokers (e.g., Pechmann et al. 2003). This has been a critical issue for public policy and public health because approximately one-half of the adolescent smokers who continue to smoke through their adult lives die from a tobacco-

Table 3. Hierarchical Logistic Regression Model Results for Adult Smokers' Intentions to Quit Smoking

\begin{tabular}{|c|c|c|c|}
\hline \multirow[b]{2}{*}{ Antismoking Predictors } & \multicolumn{3}{|c|}{ Logistic Regression Coefficients (SE) } \\
\hline & Model 1: Demographics & Model 2: Ad Campaign & Model 3: Beliefs \\
\hline Race & $-.43(.34)$ & $.09(.38)$ & $.09(.40)$ \\
\hline Age & $-.04(.01) * *$ & $-.04(.01)^{* * *}$ & $-.03(.01)^{* * *}$ \\
\hline Education & $-.06(.16)$ & $-.09(.17)$ & $-.12(.18)$ \\
\hline Gender & $-.61(.31)^{* *}$ & $-.50(.33)^{*}$ & $-.60(.35)^{* *}$ \\
\hline Attitude toward the campaign & & $.16(.08)^{* *}$ & $.13(.08)^{*}$ \\
\hline Number of campaign advertisements & & $.15(.16)$ & $.14(.16)$ \\
\hline Ad message strength & & $.20(.08) * * *$ & $.13(.09)^{*}$ \\
\hline Deceptiveness belief & & & $.53(.30)^{* *}$ \\
\hline Addictiveness belief & & & $.82(.39) * *$ \\
\hline Secondhand smoke belief & & & $-.31(.39)$ \\
\hline Restrict smoking belief & & & $.23(.14)^{*}$ \\
\hline Model $\chi^{2}$ value & $19.60 * * *$ & $45.0 * * *$ & $58.4 * * *$ \\
\hline$\chi^{2}$-change value & - & $25.4 * * *$ & $13.4 * * *$ \\
\hline Model R2 & .12 & .27 & .33 \\
\hline $\begin{array}{l}* p<.10 \\
* * p<.05 \\
* * * p<.01 \\
\text { Notes: All coefficients are unstandardized. }\end{array}$ & & & \\
\hline
\end{tabular}


related disease (e.g., Pollay et al. 1996). Given the suggested importance of the adolescent segment to the industry (Cohen 2000; WHO 2006) and the relatively stronger influence of tobacco advertising on adolescents (Pollay et al. 1996), a relevant question for policy makers is whether the findings from Study 1 for campaign effects on specific antismoking beliefs replicate for adolescent consumers. If the findings replicate, this will indicate that an overall counteradvertising campaign could produce comparable results in tests of predictions, despite the substantial differences between the adult and the adolescent populations. Therefore, Study 2 tests several of the Study 1 hypotheses on a large sample of adolescents.

\section{Study 2}

\section{Background}

Although we are not aware of prior studies that directly address ad campaign effects on specific beliefs across both adolescents and adults, some show differences in beliefs between adolescent smokers and nonsmokers. For example, Ross and Perez (1998) find that younger smokers have stronger antismoking attitudes than older smokers. This finding seems consistent with differences between adults and adolescents in their breadth of experience with smoking, amount of exposure to smoking by others, and level of tobacco promotion exposure. It can also be argued that adolescents may be more responsive to persuasive antismoking advertisements, similar to reports that sensitivity to tobacco advertising is stronger for adolescents than for adults (Pollay et al. 1996). In addition, adolescents are more selfconscious and experience more self-doubt than adults, which could partially explain why adolescents tend to respond differently than adults to the marketing of risky products, such as tobacco (Pechmann et al. 2005). Even antismoking messages aimed at adolescents may not influence (older) college-aged students in the same way (Wolburg 2006). Ross and Perez (1998) also report that nonsmokers tend to have stronger antismoking attitudes than smokers across both adolescents and adults. On balance, we anticipate that the rationale underlying the predictions of relationships for the antismoking ad campaign variables will apply to adolescents as well as adults.

Comparing adolescents with adults has important implications for public policy decisions and for advertising campaign theory. It permits an assessment of the degree to which generalizations can be made for ad campaign effects across these two target markets of consumers. If the results are similar, this will indicate that the ad-based constructs influence dependent variables similarly, which will increase confidence in the conceptual role of these variables, despite the substantial sample-based age differences and associated differences, such as lifetime levels of exposure to smoking and tobacco firms' promotions. Such comparisons also have broad implications for policy makers and advertisers, who must make decisions about campaign message themes, execution and communication, and target market issues.

In general, we believed that predictions for campaignrelated measures would have similar effects for adolescents and adult consumers, though because of differences in tobacco industry promotion exposure and specific campaign objectives, some differences in strength may be anticipated. Specifically, whereas influencing industry deceptiveness and addictiveness beliefs were objectives for both adults and adolescents, the importance of secondhand smoke was a message objective primarily targeted at the adult sample. For adolescents, there is a substantial concern to prevent smoking behavior that leads to continued smoking behavior in adulthood. For adolescents, then, goals of the campaign included reducing intentions to smoke in the near future (e.g., "Do you think you will smoke a cigarette at anytime during the next year?") rather than the consideration of quitting for current adult smokers, as Study 1 assessed.

\section{Methodology}

\section{The Antitobacco Campaign, Data Collection Procedures, and Sample}

The procedures used for Study 2 were kept as similar as possible to those of Study 1. For the adolescent campaign, four specific advertisements ("Mohammed," "FACT" "Janet Sachman," and "Patrick Reynolds") were aired on television and the radio in seven major Wisconsin markets. "Mohammed" is about a young African American man reading about the ways the tobacco companies have tried to target kids to start smoking. In "FACT" ("Fighting Against Corporate Tobacco"), a cigarette company executive is dreaming about kids tracking him down and yelling at him about the lies he has told about smoking. ("Janet" and "Patrick" were previously described as part of the adult campaign.) Telephone interviews were used to collect data from adolescents ranging in age from 12 to 18 years. Telephone numbers of potential respondents were randomly selected from a list purchased from a major list vendor. For adolescents known to be eligible for inclusion in the sample, there was a response rate of $31 \%$, and up to eight callbacks were made in attempts to reach targeted adolescents. The survey introduction indicated that the survey was asking "Wisconsin youth about their attitudes and opinions toward tobacco and other health issues." After obtaining parental permission for participation, respondents were assured that their responses would remain confidential. Parents were not informed about the specific survey questions, and they could not hear the telephone questions asked. Of the respondents, $53 \%$ were male, and the average age was 15 years. The sample sizes for analyses ranged from 900 to 901.

\section{Measures}

Whenever possible, the measures in Study 2 were kept identical to those of Study 1, including all measures of ad campaign constructs and belief-related dependent variables. Instead of respondent education level, we used the head of the household's education level for adolescents as a control variable. (Note that education/grade for adolescents is strongly and positively correlated with age, which is another control variable.) Consistent with prior studies examining adolescents and smoking (e.g., the University of Massachusetts Tobacco Study Youth Instrument, Florida's AntiTobacco Media Evaluation Survey, the CDC Youth Tobacco Survey, the Youth Risk Behavior Survey), we used prior trial smoking behavior as the smoking status variable because only a small percentage of adolescents were currently regular smokers. On the basis of these previous stud- 
ies, prior trial behavior was measured by asking the following question: "Have you ever tried cigarette smoking, even one or two puffs?" ( $1=$ yes, and $0=$ no). All measures and procedures for the youth sample were pretested with 75 respondents before we conducted the survey.

The most substantial difference in Study 2 is related to the intention measure. Adolescents were asked about their intentions to smoke in the future. In line with prior studies, three items were used: "If one of your best friends offered you a cigarette, would you smoke it?" "Do you think you will smoke a cigarette at anytime during the next year?" and "Do you think you will be smoking cigarettes five years from now?" Coefficient alpha for these three items was .85 . Coefficient alpha reliabilities for the antismoking beliefs of deceptiveness, addictiveness, and the harmfulness of secondhand smoke were $.78, .70$, and .76 , respectively, for this sample.

\section{Results}

\section{Effects on Antismoking Beliefs}

In parallel to the adult sample, we assessed the effects of the demographic (control) variables on antismoking beliefs for adolescents in the first stage of a hierarchical regression analyses. The findings appear in Model 1 in the top portion of Table 2. In terms of demographics, age range has a much stronger effect among adolescents (i.e., ages 14-18) than in the adult sample. Younger adolescents are more likely to have stronger beliefs about deceptiveness, addictiveness, and smoking restrictions than older adolescents. There was not a significant effect of age on secondhand smoke beliefs (a message theme not directed at adolescents by the campaign).

In the second stage of the model, smoking trial leads to similar effects, as does the current smoking status variable for adults in Study 1. Across all four beliefs, the smoking trial measure has a significant, negative effect $(p<.01)$, in support of $\mathrm{H}_{1}$. (However, note that for deceptiveness and addictiveness, the effect based on $\mathrm{R}$-square change values appears less strong for adolescents than for adults.) Consistent with $\mathrm{H}_{1 \mathrm{~b}}$, trial status explains the greatest variance in beliefs about restricting smoking, but in terms of addictiveness, $\mathrm{H}_{1 \mathrm{~b}}$ is not supported.

In the third stage of the hierarchical regression, we entered the ad campaign measures into the model. In the aggregate, the addition of these campaign reactions has significant effects (for all beliefs, $p<.01$ ), and the increase in $\mathrm{R}$-square for the belief dependent variables ranges from .06 to .10 .

The $\mathrm{H}_{2}$ prediction that attitude toward the ad campaign would be positively related to antismoking beliefs is supported. All the campaign coefficients are positive and significant $(p<.01$ for all except restrictions on smoking, which is significant at $p<.05) . \mathrm{H}_{3}$ predicted that prior smoking behavior would moderate the effect of attitude toward the campaign. The results in Table 2 show that interaction coefficients for prior trial behavior and attitude toward the campaign are positive and significant for all four antismoking beliefs. For the dependent variable of restrictions on smoking, there is only marginal significance $(p<$ .10). This pattern of findings supports $\mathrm{H}_{3}$ and indicates that though a favorable attitude toward the campaign has a posi- tive influence in general, it has a stronger (more positive) influence on adolescents who had tried smoking. $\mathrm{H}_{4}$ predicted that the perceived strength of the advertising message would be positively related to the antismoking beliefs. Table 2 shows that these coefficients are significant and positive $(p<.01)$ for each of the belief dependent variables.

$\mathrm{H}_{5}$ and $\mathrm{H}_{6}$ address the direct and interaction effects related to increased awareness of multiple advertisements in the campaign. The direct effect for the number of advertisements was strong and positive for the deceptiveness, addictiveness, and secondhand smoke beliefs $(p<.01)$, in support of $\mathrm{H}_{5 \mathrm{a}}-\mathrm{H}_{5 \mathrm{c}}$. There was only marginal support for restrictions on smoking $(p<.10)$. The findings for the moderating effects of trial behavior on the effects of awareness of multiple campaign advertisements are weak. There is a stronger, positive influence of the number of campaign advertisements for adolescents who had tried smoking than for those who had not in terms of beliefs for addictiveness $(p<.10)$ and secondhand smoke $(p<.05)$, offering some support for $\mathrm{H}_{6}$.

\section{Effects on Intention to Smoke}

To assess the effect of the campaign on intentions to smoke, we performed a hierarchical regression. ${ }^{6}$ In the first stage, in which we entered the demographic controls, there is a strong, positive effect of age (older adolescents are more likely to report stronger intentions to smoke) and a negative impact of the head of the household's education (i.e., more education is associated with reduced intentions). Demographics explained $8 \%$ of the variance in the adolescents' smoking intentions.

We entered smoking trial in the second stage, and it was significant $(p<.001)$, with a positive impact on smoking intentions. The F-change associated with the addition of the trial variable was 285.4, and the model R-square increased almost fourfold to .31 . In the third stage, we incrementally added the ad campaign variables to the regression model. The addition of the ad campaign variables explained a significant amount of incremental variance in intentions to smoke $(\mathrm{F}$-change $=14.0, p<.01)$. Two of the three ad construct variables had significant, negative effects on adolescents' smoking intentions. ${ }^{7}$ The standardized coefficient for attitude toward the ad campaign was $-.14(p<.01)$, and for the number of campaign advertisements, the standardized coefficient was $-.06(p<.05)$. The standardized coefficient for perceived message strength was not significant $(p>.15)$. The final model, which included demographics, smoking trial, and the ad campaign measures, explained more than

6Note that there are three major differences here from the analysis for the adult consumers in Study 1. First, for the adolescents, we have a multi-item dependent variable and thus use hierarchical multiple regression rather than the logistic regression procedure used for analyses in Study 1. Second, the dependent variable for adolescents is intent to smoke rather than intent to quit for the Study 1 adult smokers. This results in an anticipated difference in signs of the coefficients and a larger sample size for the adolescents due to no restrictions because of smoking status. Third, the effect of smoking trial for adolescents can be entered into the model because analyses are not restricted to smokers only, as in the Study 1 adult sample.

${ }^{7}$ Because predictions in $\mathrm{H}_{7}$ and $\mathrm{H}_{8}$ explicitly refer to (adult) smokers' intentions to quit in contrast to adolescents' intentions to smoke in the future, we do not formally address these specific predictions. However, the results of Study 2 show desirable campaign-related effects on intentions, though the intentions variable differs across the studies. 
one-third of the adolescents' future smoking intentions $\left(\mathrm{R}^{2}=.34\right)$.

\section{General Discussion}

\section{Summary}

If upheld, Judge Kessler's "Final Judgment and Remedial Order" will require corrective advertising from major tobacco companies on major networks' prime-time television, in major newspapers, on package onserts, and in pointof-purchase displays (U.S. v. Philip Morris USA, Inc. 2006). Beliefs that will be addressed in this advertising and promotion include the addictiveness of smoking and the harmful effects of ETS. Consistent with the court's ruling to focus antismoking promotion on beliefs associated with prior marketing of the tobacco companies, our first study question asked whether, beyond demographics and smoking status, antismoking ad campaign constructs explain additional variance in the four specific antismoking beliefs of addictiveness, secondhand smoke, deceptiveness, and smoking restrictions. Our results showed that the campaign-related variables explained incremental variance (i.e., beyond that explained by demographic and smoking status) in all four of these beliefs for both adults and adolescents. Standardized coefficients indicated that, in general, the perceptions of ad message strength had the strongest effect for adults. For adolescents, ad message strength also was significant for all beliefs, and its standardized coefficient was strongest for three of the four belief measures. (The one exception was for ETS, which was not a primary belief target for the adolescent market.) Attitude toward the campaign had a significant effect for three of the four antismoking beliefs for adults and a significant effect on all four belief measures for adolescents. In conjunction, we view these findings as supportive of both a cognitive route (i.e., through the ad message) and an affective route (i.e., the attitude toward the ad campaign) for antismoking beliefs across both adult and adolescent samples (Brown and Stayman 1992; Vakratsas and Ambler 1999).

According to tenets from IMC theory, we proposed that there would be a positive relationship between the awareness of a greater number of the campaign advertisements and antismoking beliefs. For adults, there was only marginal support for this prediction; the number of advertisements in the campaign consumers recalled had somewhat smaller standardized coefficients than the other ad campaign measures. The findings for the relationships between the number of campaign advertisements recalled and the beliefs were stronger (i.e., significant for all four belief measures) for adolescents than for adults. Pollay and colleagues' (1996) study on cigarette advertising effects finds that there is a stronger relationship between the cigarette brands chosen and cigarette advertising for adolescents than for adults. Thus, our current pattern of findings seems similar in that the exposure to a larger number of campaign advertisements influenced adolescents to a greater degree than adults. The difference in the significance and strength of coefficients for the number of advertisements between the adults and the adolescents might be due to adolescents' beliefs about smoking being somewhat more pliable when exposed to an integrated campaign than is the case for adults, who have greater experience and broader exposure to smoking.
We postulated that there would be stronger, negative antismoking beliefs for those with greater smoking exposure (i.e., beliefs would be more consistent with smoking behavior). This relationship was supported for smoking status for adults (current smoker versus current nonsmoker) and for adolescents with prior trial behavior; all coefficients across both samples were negative and significant $(p<.01)$. Although the incremental variance explained by smoking status was somewhat lower for adolescents than for adults for industry deceptiveness and ETS, in general, these findings suggest the importance of prior trial for adolescents in terms of its relationship to antismoking beliefs.

For adolescents, although there is a positive relationship between attitude toward the campaign and beliefs, trial status moderates the effect of attitude toward the campaign for all four variables (though the coefficients for restrictions on smoking and industry deceptiveness were marginal). As we postulated, the positive coefficient suggests that more favorable attitudes toward the campaign had stronger effects on antismoking beliefs for respondents with prior trial behavior than for those without trial. (However, note that the correlation between attitude toward the campaign and the beliefs is positive and significant in all cases for both smokers and nonsmokers; the positive relationship is simply stronger for the trial smokers than for the nonsmokers.) This interaction was not supported for the adults. The interaction coefficient for adults was negative and significant for the belief about banning smoking from various venues. The variance in findings across samples here may be due to differences between the adolescents who had tried smoking and the adults who, in general, had smoked for years. Regardless of their attitude toward the campaign, the adult smokers were less willing to change their attitude toward banning smoking than the adolescents who had smoked only on a trial basis and/or were less likely to view themselves as regular, confirmed smokers. Further research may also view the role of reactance theory as a partial explanation for these results. Reactance theory posits that when freedom of a specific behavior is restricted, people have stronger inclinations toward that behavior (Brehm 1966). Wolburg (2006) reports that antismoking public service announcements that employ guilt and judgmental tones induce reactance responses from smokers. In theory, reactance would encourage smokers to hold onto their habit more strongly when they believed that their freedom was being restricted, and this might result in a negative reaction to antismoking messages related to smoking restrictions and bans.

Our second research question and final set of hypotheses addressed the effect of relationships between the ad campaign constructs and antismoking beliefs on adult smokers' consideration of quitting. In our initial hierarchical logistic regression findings, younger adults and women were more likely to report positive consideration of quitting. For adolescents, however, demographic results were different. Specifically, girls and older adolescents were more likely to report increased intentions to smoke. Beyond the demographics, the campaign variables were associated with a greater likelihood that adults would indicate consideration of quitting and that adolescents would indicate lower intentions to smoke in the future. Attitude toward the ad campaign had significant and favorable effects for both adolescents and adults. Some evidence indicates that the campaign 
constructs continue to influence intent even when the focal campaign-related antismoking beliefs are included in the model, suggesting a positive role of the campaign beyond its impact on antismoking beliefs.

\section{Implications for Counteradvertising Campaigns and Public Health Policy}

In general, findings for both adults and adolescents are supportive of the potential benefits of positive consumer reactions to antismoking campaigns. As a group, the addition of the ad campaign variables in the hierarchical analyses explains $6 \%-18 \%(p s<.01)$ of the incremental variance in antismoking beliefs, thus substantially increasing the Rsquare values for antismoking beliefs across both adult and adolescent samples. These increases in variance explained suggest effect sizes in the moderate to large range for these important belief measures (Cohen 1977). As the R-square change in Table 2 shows, however, the incremental explanatory effects of the campaign vary across the adolescent and adult samples. In the case of the adult sample, there are relatively large increases in incremental variance for industry deceptiveness (18\%) and ETS (16\%) due to the addition of the campaign measures but only moderate increases of $8 \%$ for each of these beliefs for the adolescents. In addition, the standardized coefficient for the perceived message strength variable was particularly strong for adult beliefs about industry deceptiveness and ETS smoke, especially compared with the respective coefficients for adolescents. (Nevertheless, the increase for adolescents and the effects on ETS beliefs may be perceived as an impressive carryover from the adult campaign, given that beliefs about ETS were not a specific target objective for the adolescent market.) For addictiveness, however, the campaign measures increase R-square by $10 \%$ for adolescents compared with only $6 \%$ for adults. In combination, these results suggest the relative success of the campaign measures in influencing the adults' deceptiveness and ETS beliefs. The policy relevance of this finding is reinforced by the finding that industry deceptiveness is positively related to adult smokers' consideration of quitting.

Our study also found that the perception of the strength of the ad message and attitude toward the ad campaign had the strongest, positive effect across consumers' antismoking beliefs for adults and adolescents (though the strength of the effect varied across the beliefs and markets). Designing advertisements with the strongest antismoking messages (as determined through copy testing or data available for advertisements tested and used previously) while using campaign advertisements for which consumers have had favorable attitudes will aid in influencing antismoking beliefs. Such an approach has been used successfully in other public health campaign efforts, such as in the national youth antidrug media campaign (Block et al. 2002; Foley and Pechmann 2004).

Although this campaign did not explicitly attempt to influence perceptions of a ban on smoking in various public locations, this is directly linked to beliefs about ETS and is a highly controversial topic both in Wisconsin and elsewhere (e.g., Brownson et al. 1995; Foster 2005; Koch 2005). Given these facts, we were interested in whether the antismoking campaign affected consumers' beliefs about smok- ing bans. Both the attitude toward the campaign and the perceived message strength had positive effects on ban-related beliefs for adults and adolescents. For antismoking advocates concerned with banning smoking from public locations, this indicates a positive, secondary effect of counteradvertising campaigns.

We also found it intriguing that the beliefs the campaign was designed to influence and the smoking ban measure did not fully mediate the effects of the antismoking campaign measures used. This pattern may suggest another incremental effect of a campaign; that is, the campaign construct measures exert some effect on consideration of quitting/ intent to smoke beyond what can be explained merely by direct effects on targeted antismoking beliefs alone. This is consistent with arguments that some affective responses to the campaign may influence intentions that extend beyond the persuasive influence on the antismoking beliefs (Andrews et al. 2004).

Although we used demographics as control variables in our analyses, we found some notable results that might have implications for ad targeting and further research. Adult women had stronger antismoking beliefs and greater considerations of quitting than men, but female adolescents reported stronger intentions to smoke. Prior research has shown that adult women have stronger beliefs about the dangers of smoking than men (Smith and Stutts 1999). Thus, it seems logical that women would have stronger antismoking beliefs and stronger intentions to quit smoking. The findings for adolescent females' intentions to smoke is consistent with some statistics that show greater decreases in smoking rates for white male than white female adolescents (CDC 2004a). These findings collectively indicate that gender could serve as a factor in the relative receptivity of messages aimed at adults that are designed to lead to the discontinuation of smoking. For adolescents, this shows the need to target young females with tailored messages in antismoking campaigns. Previous research has suggested that more female than male adolescents stopped smoking after being exposed to long-term health-related fear appeals (Smith and Stutts 2003).

Younger adult smokers had stronger beliefs about secondhand smoke and were also more likely to consider quitting (Ross and Perez 1998), suggesting a potentially more receptive market for future antismoking campaigns. For adolescents, older teenagers appear to have stronger intentions to smoke than their younger peers, emphasizing the importance of reaching these consumers in the preteen transitional ages. This is reinforced by results that show similar effects of smoking trial by adolescents and current smoking behavior of adults. Antismoking campaigns and efforts that are successful at preventing initial trial behavior by adolescents potentially offer considerable benefits. Further research and analyses appear warranted on such demographic and targeting issues.

\section{Limitations and Further Research}

This research employed a cross-sectional field study to address predictions about the influence on adult and adolescent consumers for a counteradvertising campaign. The cross-sectional design restricts the ability to draw causal inferences about relationships between constructs. To complement these data, field studies using longitudinal data 
incorporating a single set of respondents would be desirable and could provide further insights. In addition, experimental studies that vary exposure across different regions could provide incremental information about the effectiveness of campaigns on beliefs and intentions. Similar to prior studies in the literature (e.g., Soliman, Pollack, and Warner 2004), we introduced several control variables (gender, age, education); however, additional controls, such as children at home (Study 1) and smoking status of parents (Study 2), might be used as controls in future studies. ${ }^{8}$ In addition, the effectiveness of antitobacco media campaigns may vary with various behavioral steps, such as those found in the stagesof-change framework (Prochaska, Norcross, and DiClemente 1994). For example, it would be important to know the relative percentage of smokers in precontemplative, contemplative, preparation, action, and maintenance stages to match campaign appeals and measures better (Block and Keller 1998). Furthermore, given the negative publicity surrounding the tobacco industry in recent years, there may be some concern with social desirability issues related to these antismoking beliefs. However, this study examines relationships regarding these beliefs, and prior research has shown that the effect of social desirability on relationships with other constructs is not a factor (Mick 1996). In addition, the telephone methodology we used, which allows responses to an unknown/unseen interviewer, can help minimize socially desirable responses (Mick 1996).

Other factors, such as peer pressure, smoking status of parents, and prior beliefs, have been shown to influence adolescents' smoking behavior beyond smoking advertising and promotions (DeLorme, Kreshel and Reid 2003; Smith and Stutts 1999, 2006). These factors are beyond the scope of this article, which examines both adults and adolescents, but they are still important considerations when designing antismoking campaigns. Further research that examines an integrated antismoking campaign for such a range of issues would be appropriate.

Although we believe that experiments would complement these data, this study represents a first attempt in the literature (of which we are aware) to address the relationships between antismoking campaign constructs and critical beliefs and intentions across both adult and adolescent samples. Knowledge of the similarities and differences related to effects across these different markets is of conceptual interest to those interested in persuasive communications, advertising effects, and consumer behavior, and it is of practical relevance to public health officials, consumer researchers, and advertisers who help create campaigns. In addition, there are few studies in the academic literature in marketing and advertising that have focused on campaign (rather than individual ad) effects, despite the sweeping recommendations for the integration of advertising and communication efforts (Garretson and Burton 2005; McArthur and Griffin 1997). This study offers one step toward examining effects of a campaign on beliefs and intentions across multiple relevant target markets, while attempting to under-

\footnotetext{
${ }^{8}$ Note that this would introduce differences in variables and analyses across the adolescent and adult samples, and we tried to keep such differences to a minimum.
}

stand both the overlap and the deviations in findings. However, substantial future research opportunities remain for examining such campaign-related effects for integrated advertising campaign efforts.

\section{References}

Aiken, Leona S. and Stephen G. West (1991), Multiple Regression: Testing and Interpreting Interactions. Newbury Park, CA: Sage Publications.

Ajzen, Icek and Martin Fishbein (1980), Understanding Attitudes and Predicting Social Behavior. Englewood Cliffs, NJ: Prentice Hall.

American Lung Association (2003), "Adolescent Smoking Statistics," (accessed September 29, 2006), [available at http://www. lungusa.org/site/pp.asp?c=dvLUK9O0E \&b=39868].

Andrews, J. Craig, Richard G. Netemeyer, Scot Burton, D. Paul Moberg, and Ann Christiansen (2004), "Understanding Adolescent Intentions to Smoke: An Examination of Relationships Among Social Influence, Prior Trial Behavior, and Antitobacco Campaign Advertising," Journal of Marketing, 68 (July), 110-23.

Block, Lauren G. and Punam Anand Keller (1998), "Beyond Protection Motivation: An Integrative Theory of Health Appeals," Journal of Applied Social Psychology, 27 (17), 1584-1608.

, Vicki G. Morwitz, William P. Putsis Jr., and Subrata K. Sen (2002), "Assessing the Impact of Anti-Drug Advertising on Adolescent Drug Consumption: Results from a Behavioral Economic Model," American Journal of Public Health, 92 (August), 1346-51.

Brehm, Jack Williams (1966), A Theory of Psychological Reactance. New York: Academic Press.

Brown, Steven P. and Douglas M. Stayman (1992), “Antecedents and Consequences of Attitude Toward the Ad: A MetaAnalysis," Journal of Consumer Research, 19 (June), 34-51.

Brownson R.C., J. Davis, J. Jackson-Thompson, and J. Wilkerson (1995), "Environmental Tobacco Smoke Awareness and Exposure: Impact of a Statewide Clean Indoor Air Law and the Report of the U.S. Environmental Protection Agency," Tobacco Control, 4 (June), 132-38.

Burke, Marian and Julie Edell (1989), "The Impact of Feelings on Ad-Based Affect and Cognition," Journal of Marketing Research, 26 (February), 69-83.

CDC (2004a), "Cigarette Use Among High School Students: United States, 1991-2003," (accessed October 4, 2006), [available at http://www.cdc.gov/mmwr/preview/mmwrhtml/mm 5323a1.htm].

(2004b), "Effect of Ending an Antitobacco Youth Campaign on Adolescent Susceptibility to Cigarette Smoking: Minnesota, 2002-2003," (accessed October 2, 2006), [available at http://www.cdc.gov/mmwr/preview/mmwrhtml/mm5314a1. htm].

(2006), "Tobacco Information and Prevention Source," (accessed February 26, 2007), [available at http://www.cdc.gov/ tobacco/overview/Fast_Facts.htm].

Cohen, Jacob (1977), Statistical Power Analysis for the Behavioral Sciences. New York: Academic Press.

Cohen, Joel B. (2000), "Playing to Win: Marketing and Public Policy at Odds over Joe Camel," Journal of Public Policy \& Marketing, 19 (Fall), 155-67. 
Council of American Survey Research Organizations (1982), "On the Definition of Response Rates," Council of American Survey Research Organizations special report, Port Jefferson, New York.

DeLorme, Denise E., Peggy J. Kreshel, and Leonard N. Reid (2003), "Lighting Up: Young Adults' Autobiographical Accounts of Their First Smoking Experiences," Youth \& Society, 34 (June), 468-96.

Fiore, Michael C., Robert T. Croyle, Susan J. Curry, Charles M. Cutler, Ronald M. Davis, Catherine Gordon, et al. (2004), "Preventing 3 Million Premature Deaths and Helping 5 Million Smokers Quit: A National Action Plan for Tobacco Cessation," American Journal of Public Health, 94 (February), 205-210.

Foley, Diane and Cornelia Pechmann (2004), "The National Youth Anti-Drug Media Campaign Copy Test System," Social Marketing Quarterly, 10 (2), 34-42.

Foster, Richard (2005), "Editorial: Enact Statewide Smoking Ban," Milwaukee Journal Sentinel, (April 26), (accessed August 21, 2006), [available at http://www.jsonline.com].

Framework Convention Alliance for Tobacco Control (2006), "Tobacco Advertising and Promotion," (accessed August 17, 2006), [available at http://fctc.org/factsheets/9.pdf].

Garretson, Judith A. and Scot Burton (2005), "The Role of Spokescharacters as Advertisement and Package Cues in Integrated Marketing Communications," Journal of Marketing, 69 (October), 118-32.

Haley, Russell I. and Allan L. Baldinger (1991), "The ARF Copy Research Validity Project," Journal of Advertising Research, 31 (2), 11-32.

Haugvedt, Curtis P., David W. Schumann, Wendy L. Schneier, and Wendy L. Warren (1994), "Advertising Repetition and Variation Strategies: Implications for Understanding Attitude Strength," Journal of Consumer Research, 21 (June), 176-89.

$\mathrm{Hu}$, Teh-Wei, Hai-Yen Sung, and Theodore E. Keeler (1995), "Reducing Cigarette Consumption in California: Tobacco Taxes Vs. an Anti-Smoking Media Campaign," American Journal of Public Health, 85 (September), 1218-22.

Jamieson, Patrick and Daniel Romer (2001), "What Do Young People Think They Know About the Risks of Smoking?" in Smoking: Risk, Perception \& Policy, Paul Slovic, ed. Thousand Oaks, CA: Sage Publications, 51-63.

Koch, Wendy (2005), "39\% Live in Areas Limiting Smoking," USA Today, (December 28), C1.

Longo, Daniel R., Jane C. Johnson, Robin L. Kruse, Ross C. Brownson, and John E. Hewett (2001), "A Prospective Investigation of the Impact of Smoking Bans on Tobacco Cessation and Relapse," Tobacco Control, 10 (September), 267-72.

Lutz, Richard J. (1985), "Affective and Cognitive Antecedents of Attitude Toward the Ad: A Conceptual Framework," in Psychological Processes and Advertising Effects: Theory, Research, and Application, Linda F. Alwitt and Andrew A. Mitchel, eds. Hillsdale, NJ: Lawrence Erlbaum Associates, 45-63.

McArthur, David N. and Tom Griffin (1997), "A Marketing Management View of Integrated Marketing Communications," Journal of Advertising Research, 37 (5), 19-26.

McGrath, John M. (2005), "A Pilot Study Testing Aspects of the Integrated Marketing Communications Concept," Journal of Marketing Communications, 11 (September), 191-214.

McMillen, Robert C., Jonathan P. Winickoff, Jonathan D. Klein, and Michael Weitzman (2003), "U.S. Adult Attitudes and Prac- tices Regarding Smoking Restrictions and Child Exposure to Environmental Tobacco Smoke: Changes in the Social Climate from 2000-2001," Pediatrics, 112 (July), e55-e60.

Mick, David Glen (1996), "Are Studies of Dark Side Variables Confounded by Socially Desirable Responding? The Case of Materialism," Journal of Consumer Research, 23 (September), 106-119.

National Cancer Institute (1999), Smoking and Tobacco Control Monograph 10: Health Effects of Exposure to Environmental Tobacco Smoke. Bethesda, MD: National Cancer Institute.

Netemeyer, Richard G., J. Craig Andrews, and Scot Burton (2005), "Effects of Antismoking Advertising-Based Beliefs on Adults Smokers' Consideration of Quitting," American Journal of Public Health, 95 (6), 1062-1066.

Pechmann, Cornelia, Linda Levine, Sandra Loughlin, and Frances Leslie (2005), "Impulsive and Self-Conscious Adolescents' Vulnerability to Advertising and Promotion," Journal of Public Policy \& Marketing, 24 (Fall), 202-221.

- Guangzhi Zhao, Marvin E. Goldberg, and Ellen Thomas Reibling (2003), "What to Convey in Antismoking Advertisements for Adolescents? The Use of Protection Motivation Theory to Identify Effective Message Themes," Journal of Marketing, 67 (April), 1-18.

Petty, Richard E. and John T. Cacioppo (1981), Attitudes and Persuasion: Classic and Contemporary Approach. Dubuque, IA: William C. Brown.

- and (1986), Communication and Persuasion: Central and Peripheral Routes to Attitude Change. New York: Springer-Verlag.

Pollay, Richard W., S. Siddarth, Michael Siegel, Anne Haddix, Robert K. Merritt, Gary A. Giovino, and Michael P. Eriksen (1996), "The Last Straw? Cigarette Advertising and Realized Market Shares Among Youths and Adults, 1979-1993," Journal of Marketing, 60 (April), 1-16.

Prochaska, James O., John C. Norcross, and Carlo C. DiClemente (1994), Changing for Good: A Revolutionary Six-Stage Program for Overcoming Bad Habits and Moving Your Life Positively Forward. New York: Harper Collins Publishing.

Romer, Daniel and Patrick Jamieson (2001), "Advertising, Smoker Imagery, and the Diffusion of Smoking Behavior," in Smoking: Risk, Perception \& Policy, Paul Slovic, ed. Thousand Oaks, CA: Sage Publications, 127-55.

Ross, Nancy and Claudio Perez (1998), “Attitudes Towards Smoking," Health Reports, 10 (Winter), 23-33.

Rucker, Derek D. and Richard E. Petty (2006), "Increasing the Effectiveness of Communications to Consumers: Recommendations Based on Elaboration Likelihood and Attitude Certainty Perspectives," Journal of Public Policy \& Marketing, 25 (Spring), 39-52.

Schultz, Don E., Stanley I. Tannenbaum, and Robert F. Lauterborn (1993), Integrated Marketing Communications. Lincolnwood, IL: NTC Publishing Group.

Sherif, Muzafer and Carl I. Hovland (1961), Social Judgment. New Haven, CT: Yale University Press.

Shimp, Terence A. (2007), Advertising, Promotion and Other Aspects of Integrated Marketing Communications, 7th ed. Mason, OH: Thomson/South-Western.

Siegel, M. (2002), "The Effectiveness of State-Level Tobacco Control Interventions: A Review of Program Implementation 
and Behavioral Outcomes," Annual Review of Public Health, 23, $45-71$.

Smith, Karen H. and Mary Ann Stutts (1999), "Factors That Influence Adolescents to Smoke," Journal of Consumer Affairs, 33 (Winter), 321-57.

and - (2003), "Effects of Short-Term Cosmetic Versus Long-Term Health Fear Appeals in Anti-Smoking Advertisements on the Smoking Behaviour of Adolescents," Journal of Consumer Behaviour, 3 (December), 157-77.

and - (2006), "The Influence of Individual Factors on the Effectiveness of Message Content in Antismoking Advertisements Aimed at Adolescents," Journal of Consumer Affairs, 40 (Winter), 261-93.

Soliman, Soheil, Harold A. Pollack, and Kenneth Warner (2004), "Decrease in Prevalence of Environmental Tobacco Smoke Exposure in the Home During the 1990s in Families with Children," American Journal of Public Health, 94 (February), 314-20.
U.S. v. Philip Morris USA Inc. (2006), Civil Action No. 99-2496 (GK), Order No. 1015 ("Final Judgment and Remedial Order"), (U.S. District Court), (August 17).

Vakratsas, Demetrios and Tim Ambler (1999), "How Advertising Works: What Do We Really Know?" Journal of Marketing, 63 (January), 26-43.

WHO (2006), "The Tobacco Industry Documents: What They Are, What They Tell Us, and How to Use Them," (accessed August 16, 2006), [available at http://www.who.int/tobacco/ communications/TI_manual_content.pdf].

Wolburg, Joyce M. (2006), “College Students’ Responses to AntiSmoking Messages: Denial, Defiance, and Other Boomerang Effects," Journal of Consumer Affairs, 40 (2), 294-322.

Zinkhan, George M. and Scot Burton (1989), "An Examination of Three Multidimensional Profiles for Assessing Consumer Reactions to Advertisements," Journal of Advertising, 18 (4), 6-13. 